\section{Etho-Ecological Adaptations in the Great Frigate-bird}

RECENT work on the great frigate-bird Fergata minor of the Galapagos island of Tower disclosed a unique syndrome of adaptations to a markedly erratic and nonseasonal food supply. The Fergatidae have not only evolved a strongly aerial life, becoming morphologically specialized with reduced tarsi, tiny unwebbed zygodactylous feet, vestigial uropygial gland (plumage waterproofing unnecessary) and a ratio of wing span to weight greater than in any other sea-bird (about four times as great as the comparably sized, sympatric and far-flying waved albatross (Diomedea irrorata)) but, if Fergata minor is typical, they also differ from all other members of their order Pelicaniformes in several basic reproductive mechanisms.

The complete breeding cycle takes one and a half to three times as long as in any other member of the order; from the date of egg laying to independence of the young requires about 400 days or more (about 10-20 days sexual display and pair formation, 55 days incubation period, 130-160 days fledgling period and up to 180 days or more post-fledgling feeding of the juvenile by the parents). The length of the frigate breeding cycle reflects the slow growth of the young and their difficult transition to independence. Slow growth and fasting ability are valuable adaptations to an irregular food supply, while the prolonged postfledgling feeding, the longest on record for any sea-bird, reflects the non-seasonal nature of the food supply and the specialized frigate feeding technique of snatching food in flight and piracy from other species, which takes a long time to perfect (juveniles rarely attempt piracy). Even after 6 months of partial independence, free ranging but also fed by parents, the juveniles lost weight from an average 1,083 $\mathrm{g}$ in April 1964 to $983 \mathrm{~g}$ in June 1964, and several died (at $600 \mathrm{~g}$ ) when their parents stopped feeding them.

The long reproductive cycle prevents annual breeding, and individual frigates, if successful, apparently breed every second year (the main laying period on Tower seems to fall roughly at the same time each year). Two important results of this are the lack of a permanent nest site and pair bond, and the associated evolution of special sexual and agonistic behaviour.

Sea-birds show marked site and mate fidelity the adaptive value of which in enhancing breeding success has now been demonstrated for the kittiwake Rissa tridactyla ${ }^{1}$. In the great frigate, fidelity to the local area probably remains, but another pair may be occupying the nest site (this probably explains why one often sees a displaying male alongside a fledged juvenile) especially in favoured areas such as the dense shrub Cryptocarpus pyriformes at the head of Darwin Bay on Tower, where 212 pairs nested in about 4,500 square yards in site com. petition with $300-400$ pairs of red-footed boobies Sula sula. Because sites are thus potentially transitory, the whole mechanism of pair formation, whereby the male establishes and in later years returns to the site and is later joined by the female, is altered in the great frigate. Males show no territorial aggression or nest building behaviour in the early stages of their ritualized sexual display, whereas in other sea-birds this is precisely when aggressive behaviour reaches its highest intensity. Consequently, male frigates can display unanimously in a close group greatly enhancing its visual and auditory impact to females flying over. Display nuclei initiated by one or two males grow rapidly and, after some have successfully formed pairs (which will breed on the male's display site), the remainder form or join another nucleus elsewhere. This mechanism of pair formation reduces the chances of the same pair members re-uniting in successive cycles; each male displays indiscriminately at the beginning of each reproductive cycle and, although previous areaimprinting and pair-conditioning can increase the pro- portion of re-pairings to more than random, it is certain that pair bonds are notably impermanent compared with those of other Pelicaniformes.

Agonistic behaviour and pair interactions are poorly developed in great frigates; at no stage do they perform aggressively motivated, ritualized site ownership display. In addition, pair members show merely a highly undifferentiated form of interaction and even this is confined to the period of pair formation. After egg laying, nest relief is accomplished without a meeting ceremony or any preleaving display. Incubation stints last 10 to 15 days and the incubation period is 55 days, so that nest reliefs are relatively few. An important corollary of relatively weak territorial behaviour and pair bond is the high degree of site and mate usurpation, with consequent loss of egg or chick (205 out of 315 eggs laid between February and May 1964 were lost, mainly in this way). Thirty-one of 110 chicks were killed, mainly by intruding frigates taking over the nest in the absence of the owners and, in two cases, the male owner returning to find an intruding male evicting his chick did not attempt to displace him. The high breeding failure means that the great frigate population on Tower is not divided into two reproductively isolated halves, because failed breeders can later try again with the next main onset of breeding in the colony when successful pairs are still completing their cycle.

It seems that despite the disadvantages of their methods of site maintenance and pair relations, great frigate-birds have evolved them as part of an etho-ecological system. adapted overwhelmingly to meet the demands of an environment the dominant characteristic of which is the irregular food supply. Their reactions to this, in length of breeding cycle and feeding specializations, have brought in their train a basic reorganization of pair and social behaviour in which the Fergatidae now differ strongly from other members of the Pelicaniformes.

\section{J. B. NeLson}

Department of Zoology,

University of Aberdeen.

${ }^{1}$ Coulson, J. C., Animal Behaviour, 14, 189 (1966).

\section{Anaerobic Respiration in a Cyprinoid Fish Rasbora daniconius (Ham)}

Asphyxia, anoxia and hypoxia occur only when the ambient oxygen and carbon dioxide in water reach threshold level. Lethal or critical content of oxygen has been determined by various authors ${ }^{1-8}$ in many fishes, the time of anoxia being totally dependent on the composition of the surrounding water. In the present investigations one fish was introduced into a glass jar contrining $2 \cdot 6$ l. of tap water; two such experiments were performed simultaneously. The initial concentration of oxygen in water, measured by Winkler's method, was $4 \mathrm{ml}$./l. and that of the free carbon dioxide, measured by titration with sodium hydroxide with phenothalein as indicators, was $22 \mathrm{mg} / \mathrm{l}$. The $p \mathrm{H}$ of the water was 8.5 . The fish in one experiment weighed $4 \cdot 8 \mathrm{~g}$. The jars were hermetically sealed and covered with cardboard on all sides. The fish was expected to die by suffocation as the oxygen concentration was continuously decreasing, but it survived well for 81 days. During this period the temperature of the water varied between $29^{\circ} \mathrm{C}$ and $33^{\circ} \mathrm{C}$. The weight of the fish after death was only $1.08 \mathrm{~g}$, thereby showing a marked reduction by $3 \cdot 72 \mathrm{~g}$. The concentration of oxygen in water after the death of the fish was found to be nil while that of carbon dioxide was $39 \mathrm{mg} / \mathrm{l}$. The $p H$ was $9 \cdot 9$. In the other experiment in similar conditions the fish survived for 102 days.

Four hours before actual death peculiar respiratory distress in the form of an uneasiness and random movements developed in the experimental fish. The fish behaved as if it were violently irritated, and the respiratory 